\title{
Young women with acute myocardial infarction. Where to look for the causes?
}

\author{
Sylwia Iwańczyk, Aneta Klotzka, Patrycja Woźniak, Marek Grygier, Maciej Lesiak \\ $1^{\text {st }}$ Department of Cardiology, Poznan University of Medical Sciences, Poznań, Poland
}

Correspondence to:
Sylwia Iwańczyk, MD,
$1^{\text {st }}$ Department of
Cardiology,
Poznan University of
Medical Sciences,
Długa 1/2,
61-848 Poznań, Poland,
phone: +48 61 854 92 22,
e-mail:
syl.iwanczyk@gmail.com
Copyright by the Author(s),
2021
Kardiol Pol. 2021;
79 (10): 1143-1144;
DOl: 10.33963/KP.a2021.0061
Received:
June 22, 2021
Revision accepted:
July 13, 2021
Published online:
July 14, 2021

Correspondence to: Sylwia Iwańczyk, MD, epartment of Poznan University of Medical Sciences, 61-848 Poznań, Poland phone: +4861 8549222 syl.iwanczyk@gmail.com Copyright by the Author(s),

79 (10): $1143-1144$ DOl: 10.33963/KP.a2021.0061 July 13, 2021 July 14, 2021
In recent decades, the incidence of myocardial infarction (MI) has significantly declined in the general population [1]. However, MI rates in young people, especially women, have not decreased as much as among older adults. On the contrary, based on some studies, the incidence of $\mathrm{Ml}$ in young people has increased over the past few years [2]. The underlying reason is probably an underestimation of cardiovascular risk and the resulting lack of treatment for young people [3]. Nevertheless, as the current case shows, an acute MI can also occur in young people without typical cardiovascular risk factors. Moreover, in the current pandemic, a COVID-19 infection should be additionally considered as a possible risk factor for an acute MI.

A 27-year-old woman with neither cardiovascular risk factors nor a history of coronary artery disease (CAD) was admitted to the local hospital with an ST-segment elevation myocardial infarction (STEMI) of an anterior wall. Importantly, RT-PCR (real-time polymerase chain reaction) tests for COVID-19 were negative, and she did not present any symptoms of SARS-CoV-2 infection earlier. Coronary angiography revealed a total occlusion of the left descending artery (LAD) in the middle segment (Figure $1 \mathrm{~A}$ ), requiring in an immediate primary percutaneous coronary intervention. Despite numerous attempts, it was not feasible to pass the guidewire distally through the lesion and restore the arterial flow. The patient was treated with heparin and a glycoprotein (GP) IIb/IIla inhibitor in a bolus, followed by an intravenous infusion, and was transferred to the intensive cardiology care unit. A control coronary angiography performed two days later showed persistent LAD occlusion (Figure 1B). The second percutaneous coronary intervention attempt was also unsuccessful.

Within a few months, the patient was admitted to our hospital for another attempt of the $L A D$ recanalization. On admission, she presented the Canadian Cardiovascular Society class III symptoms. Cardiac magnetic resonance confirmed post-infarction transmural scar of the interventricular septum and apex area with segmental impairments in contractility and preserved global ejection fraction

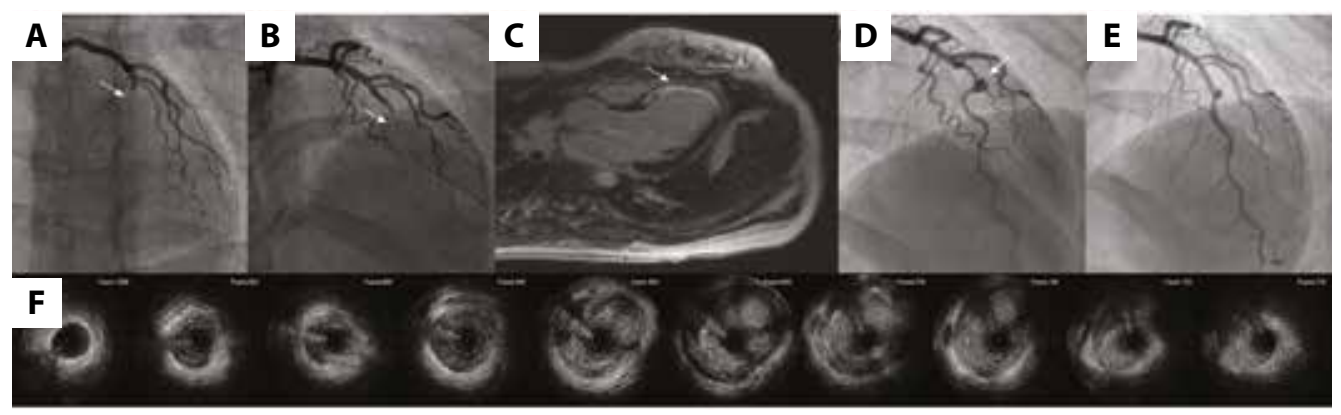

Figure 1. A. Anteroposterior cranial view of LCA. Acute occlusion of $L A D$ artery (arrow). B. RAO view of LAD after 2 days with persistent $L A D$ occlusion (arrow). C. Cardiovascular magnetic resonance, 4-chamber view. Late gadolinium enhancement of the interventricular septum and apex area (arrow). D. RAO view of LAD after 4 months with patent severe stenosed LAD and aneurysm in the middle segment (arrow). E. IVUS imaging of middle segment of LAD. F. RAO view of LAD after percutaneous coronary intervention with stent implantation in the middle segment Abbreviations: IVUS, intravascular ultrasound; LAD, left anterior descending; LCA, left coronary artery; RAO, right anterior oblique 
(59\%) (Figure 1C). Coronary angiography demonstrated recanalized LAD with severe stenosis and a saccular aneurysm distal to the target lesion (Figure 1D). The size of the aneurysm was evaluated as $7.8 \mathrm{~mm} \times 8.7 \mathrm{~mm}$ on quantitative coronary angiography. In the arterial segments, both proximally and distally to the lesion, intravascular ultrasound (IVUS)showed a normal vessel wall free of atherosclerotic lesions (Figure 1E). Furthermore, an intima dissection was confirmed, significantly narrowing the vessel lumen. Only after pre-dilatation of the lesion with a noncompliant (NC) balloon, was the drug-eluting stent (XIENCE PRO $2.5 \times 23 \mathrm{~mm}$, Abbott Vascular, Chicago, IL, US) successfully implanted across the diagonal branch. The procedure was finalized with Proximal Optimalisation Technique using a $3.0 \mathrm{~mm}$ NC balloon (Figure 1F). IVUS confirmed optimal stent apposition as well as residual flow in the saccular aneurysm.

In conclusion, the most probable cause of our patient's condition is a coronary aneurysm, as it poses a risk of Ml, arrhythmias, or even sudden cardiac death. The causative factors behind coronary aneurysms include atherosclerosis, inflammatory diseases, congenital or iatrogenic arteries defects, connective tissue disorders, or drug-induced side effects [4].

\section{Article information}

Conflict of interest: None declared.

Open access: This article is available in open access under Creative Common Attribution-Non-Commercial-No Derivatives 4.0 International (CC BY-NC-ND 4.0) license, allowing to download articles and share them with others as long as they credit the authors and the publisher, but without permission to change them in any way or use them commercially. For commercial use, please contact the journal office at kardiologiapolska@ptkardio.pl.

How to cite: IwańczykS, Klotzka A, WoźniakP, et al. Young women with acute myocardial infarction. Where to look for the causes? Kardiol Pol. 2021; 79(10): 1143-1144, doi: 10.33963/KP.a2021.0061.

\section{REFERENCES}

1. Reynolds K, Go AS, Leong TK, et al. Trends in incidence of hospitalized acute myocardial infarction in the Cardiovascular Research Network (CVRN). Am JMed. 2017; 130(3):317-327, doi: 10.1016/j.amjmed.2016.09.014, indexed in Pubmed: 27751900.

2. Arora S, Stouffer GA, Kucharska-Newton AM, et al. Twenty year trends and sex differences in young adults hospitalized with acute myocardial infarction. Circulation. 2019; 139(8): 1047-1056, doi: 10.1161/CIRCULATIONAHA.118.037137, indexed in Pubmed: 30586725.

3. DeFilippis EM, Singh A, Divakaran $S$, et al. Cocaine and marijuana use among young adults with myocardial infarction. J Am Coll Cardiol. 2018; 71(22): 2540-2551, doi: 10.1016/j.jacc.2018.02.047, indexed in Pubmed: 29535062.

4. IwańczykS, Borger M, Kamiński M, et al. Inflammatory response in patients with coronary artery ectasia and coronary artery disease. Kardiol Pol. 2019; 77(7-8): 713-715, doi: 10.33963/KP.14812, indexed in Pubmed: 31066726. 